\title{
O desafio da sustentação da palavra entre pares: sobre política e psicanálise ${ }^{*}$
}

\section{The challenge of sustaining the word among peers: about politics and psychoanalysis}

A partir da experiência de diálogo estabelecida entre psicanalistas em torno de inquietações clínicas, discutimos o desafio da sustentação da palavra entre pares, nas tensões, identificações e pedidos de reconhecimento que dali emergem. Buscamos problematizar os desafios que as ambições narcísicas de cada um, num cenário em que as posições entre pares não estão previamente hierarquizadas, trazem para as possibilidades de vinculação horizontal de reciprocidade, fazendo ver a dimensão política que incide em configurações grupais. Para tanto, propomos esta reflexão a partir do diálogo interdisciplinar entre saberes distintos, entre psicanálise e filosofia. Consideramos que entre diferenças e igualdade, desamparo e busca por reconhecimento, a sustentação da palavra é o frágil recurso capaz de dar sentido à experiência do sujeito na assembleia dos outros.

Palavras-chave: Psicanálise, política, singularidade, igualdade, reconhecimento

*1Trabalho apresentado no evento Entretantos II: 30 anos de Psicanálise e Política, promovido pelo Departamento de Psicanálise do Instituto Sedes Sapientiae, entre os dias 17 de setembro e 29 de outubro de 2016, em São Paulo. É fruto do trabalho desenvolvido pelo grupo "Inquietações da Clínica Cotidiana" do Departamento de Psicanálise do Instituto Sedes Sapientiae.

*2 Instituto Sedes Sapientiae (São Paulo, SP, Brasil). 
Relações de força nos rodeiam e nos sustentam, nos tantos arranjos coletivos de que participamos, nos constituímos como sujeitos e atuamos como agentes. Destacar a questão política, entre psicanalistas, como vários colegas têm feito ultimamente, é um ganho para a psicanálise que recriamos, na implicação deste saber e da prática clínica nas questões prementes de nosso momento histórico, considerando os ganhos possíveis oriundos da reflexão que fazemos sobre nosso lugar e nossa prática em meio a uma cena social complexa, pulsante e provocadora. Ganhos também possíveis a partir de reflexões teóricas necessárias a sua própria sustentação — tanto do ponto de vista da posição assumida, quanto da prática a ser promovida - capazes de oferecer caminhos de análise para nossa experiência e para as proposições éticas que defendemos. Ganhos que possam vir de nossa contribuição para o debate público, quando conseguimos escutar os ditos que se perdem na surdez de tantos, em meio aos embates sociais, e formular questões e propostas de sentido acerca de nossas realidades.

A partir da experiência de discussão de casos clínicos entre pares numa instituição de psicanálise, nos propomos a analisar o que pode ser construído durante o percurso e os desafios enfrentados numa relação horizontal entre pares. São encontros mensais que vêm ocorrendo há vários anos, entre os membros desta instituição, em torno da reflexão sobre a prática cotidiana, o que os idenfica como semelhantes e fundamenta sua inserção institucional. $\mathrm{O}$ dispositivo utilizado prevê a apresentação de um fragmento clínico por algum dos membros, sendo então comentado pelos demais, sem a participação direta de quem apresentou; ressalvas quanto a importância do sigilo e o caráter horizontal do diálogo são os parâmetros retomados a cada encontro. $\mathrm{O}$ espaço de diálogo cultivado entre pares, nesses encontros, distintos de um trabalho de supervisão, ganha destaque na experiência dos participantes, a partir de seus relatos, que aqui nos dispomos a refletir.

Qual a sustentação da palavra nesse encontro entre pares, que colocam em pauta um ofício solitário compartilhado? Qual o fundamento da condição de horizontalidade estabelecida nos encontros que, 
diferentemente da dinâmica transferencial, alude à simetria que sustenta a reunião de profissionais reunidos em torno de identificações por meio da instituição? Qual a política desse dispositivo, sustentado pela palavra durante cada encontro, em seus diferentes momentos? Tal discussão parte da reflexão sobre o dispositivo lá praticado, mas o ultrapassa, pois trata da utopia da sustentação de um diálogo entre pares que se organizam numa instituição pautada por hierarquias e ditames de funcionamento próprios. Logo, trata da tensão entre as dimensões de horizontalidade e de desigualdade que configuram a política de cada organização em suas distintas configurações.

\section{As políticas do humano e a denúncia das desigualdades}

Partamos da noção de política. É possível considerá-la a partir de duas vertentes presentes nas ciências humanas: a do conflito e a do consenso. A primeira problematiza os impasses do encontro entre os homens que em desigualdade se polarizam; já a segunda propõe uma perspectiva propositiva, ao indicar um projeto tangível para o encontro humano, capaz de estabelecer um arranjo coletivo passível de entendimento (Ricoeur, 2006). De nosso ponto de vista, ambas são úteis ou mesmo necessárias, ao mostrarem, cada qual por sua parte, dois lados do campo de forças que pauta a existência humana em sua configuração coletiva e complexidade social.

Rancière (1996) segue a primeira trilha. Fazendo jus à herança francesa da ilustração, defende a igualdade de capacidades mentais entre os seres falantes como condição absoluta de toda ordem social. Questiona aqueles que, em nome do combate às desigualdades socioeconômicas, posicionam a igualdade entre os humanos como fim último de uma tarefa a ser empreendida, o que vem a pôr a desigualdade, por sua vez, como referência de seu olhar, sem necessariamente se darem conta disso: a partir do olhar de seu salvador, promotor de uma igualdade a ser conquistada, o outro é submetido a uma posição de inferioridade, desigual no exercício de sua consciência. O que devia ser um caminho promotor da igualdade, denuncia o autor, acaba por promover o inverso, reproduzindo a desigualdade que almejava combater, ainda que na melhor das intenções (Rancière, 2013).

Argumenta o autor que em relação às capacidades mentais do humano, conhecemos apenas seus efeitos, conforme as condições em que cada uma pode ser desenvolvida, pois não conseguimos, a rigor, medi-las enquanto potência. Posto isso, melhor será apostar na igualdade entre as inteligências, 


\section{LITERATURA, ARTE, CULTURA}

considerando os efeitos deste princípio, em detrimento daquele que advoga em favor da diferença. Isto porque anunciar a inteligência humana de alguém é, sobretudo, um ato de nomeação, a partir do qual cada sujeito pode se ver reconhecido por um outro e reconhecer-se em suas capacidades, conforme o uso de sua vontade e as necessidades a que está exposto (2013). Anunciar a igualdade das mesmas é, portanto, um ato político, que faz uso do peso das palavras diante do campo de forças que atuam nas redes de relações entre os humanos, tal como se organizam e se institucionalizam.

Se para Rancière as relações humanas estão pautadas, fundamentalmente, nas disputas de forças entre uns e outros, ele não nomeia tal dimensão da experiência humana como política, o que viria a diluir sua importância, generalizando-a para todas as dimensões do humano, comprometendo assim sua utilidade. Para ele, política não é apenas o exercício de dominação (que seria o uso demasiadamente genérico das relações de força), nem a deliberação sobre o bem comum (que nega a imposição de um consenso de uns sobre outros, à revelia), ou mesmo a luta entre pobres e ricos (que, ainda que porte uma verdade sobre o embate das forças sociais, atribui categorias que definem os sujeitos a partir da desigualdade, como condições prévias aos sujeitos). Política é, antes, o momento em que se anuncia a partilha desigual entre os humanos, é quando se coloca em xeque duas lógicas desiguais, dois mundos não partilhados, entre aqueles que não são reconhecidos como seres falantes, e os demais, que não os reconhecem como tais; é quando aquele que não toma a palavra, o faz, anunciando sua condição de falante; quando a quem não cabia ir ao shopping divertir-se, visto como um serviçal, se assume usuário com direito a um rolezinho; é quando o paradigma da desigualdade é negado, por meio da afirmação (afirma e faz ação) da não diferença (portanto, da igualdade) entre as capacidades mentais dos humanos (Rancière, 1996). A instauração de leis, a estrutura de representação social e as operações que buscam "a agregação e o consentimento das coletividades, a organização de poderes, a distribuição de lugares e funções e os sistemas de legitimação dessas distribuições" (p. 41) são, em contrapartida, o que Rancière chama não de política, como usualmente ocorre, mas de polícia, pelo agenciamento que realiza em favor da partilha entre desiguais. A ordem social, consequentemente, é fruto dessa polícia, que lhe dá sustentação e, por desdobramento, "toda instituição é uma explicação em ato da sociedade, uma encenação da desigualdade" (Rancière, 2013, p. 146). A desigualdade acompanha a história da humanidade em seus arranjos sociais, mas tal constatação não é justificativa suficiente para defender sua naturalização. 
Para o autor, inspirado nos ares da ilustração, o que define a condição humana em seu fundamento é, inversamente, a igualdade da capacidade mental atribuída a todos, em igual proporção, constatada a partir da emergência da desigualdade instaurada e propagada na cena social. A igualdade é a aposta que se faz, de antemão, na capacidade de cada um poder responder por sua ação, de poder agir de acordo com sua vontade, caso o meio lhe dê condições para fazer uso de seus recursos próprios. Defender a igualdade entre os humanos é, com Rancière, menos uma constatação científica (impossível, em última instância), do que um ato político em si, que faz uso do peso das palavras no campo de forças das relações humanas, a partir do lugar privilegiado que os discursos científico ou filosófico conquistaram na modernidade.

Para a psicanálise, tradicionalmente comprometida com a égide da singularidade, a igualdade é uma referência tradicionalmente associada à condição dos indivíduos que compõem massas ou, mais precisamente, ao processo de indiferenciação que aí incide (Freud, 1921/1993a) . Conforme descreve Freud, a massa é fruto da provocação narcísica que cada sujeito vive ao se identificar maciçamente com o todo de um corpo indiferenciado, tal como se caracteriza a massa, que se organiza em torno da figura de seu líder ou daquilo que ocupa seu lugar. Dessa perspectiva, a igualdade tende a ser vista como negação da diferença, fruto do desejo narcísico em favor do pertencimento a um coletivo indiferenciado, favorecendo assim a desconsideração das peculiaridades e diversidade da experiência humana em sua pulsante e criativa potência simbólica, ou, ainda, da coerção exercida pela porção hegemônica do corpo social sobre o elemento destoante minoritário ou mais frágil que diante dele sucumbe. Lembramos aqui da ressalva que Freud $(1930 / 1992 b)^{2}$ faz ao comunismo e ao combate à desigualdade econômica, em "O mal-estar...", deixando clara sua posição a respeito do tema: "a natureza, ao dotar os indivíduos de aptidões físicas e talentos intelectuais desiguais ao extremo,

${ }^{1}$ Nessa linha de pensamento encontra-se a sociabilidade sincrética descrita por Bleger, pautada pela indiferenciação entre os indivíduos, fundamento de qualquer grupamento humano (Kaes et al., 1991). Vários autores discutem esse tema, como Laclau, que busca trazer nuance à homogeneidade das coletividades, da perspectiva que "em todas formações hegemônicas, as identidades populares sempre constituem pontos de tensão/ negociação entre a universalidade e a particularidade" (Laclau, 2013, p. 156).

${ }^{2}$ Para uma discussão sobre a posição de Freud a respeito da obra de Marx, ver Hilário, 2014. 


\section{LITERATURA, ARTE, CULTURA}

estabeleceu injustiças contra as quais não há salvação" (p. 110). Para ele, portanto, a natureza humana é em si desigual.

Há diferenças quanto às diferenças humanas para estes autores, Freud e Rancière. Suas perspectivas são distintas, pois se ambos discutem a condição humana, um aborda o tema sob a ótica do desejo e do inconsciente, que o leva a realçar as (pequenas ou grandes) diferenças entre os humanos, e o outro o faz da perspectiva ontológica da filosofia política que lhe permite questionar a desigualdade (de forças, de direitos, de reconhecimento social) estabelecida na relação entre os entes humanos, anunciando a igualdade como ideal político a ser defendido. Para o primeiro, o destaque às diferenças dos sujeitos - sua singularidade - é caminho necessário para mostrar a sexualidade que subjaz recalcada ante os ditames da vida social vigente, aquela que identifica cada sujeito às funções sociais que de algum modo assume, conforme os ditames prevalentes nas organizações humanas, marcadas por hierarquias e tradições. Para o segundo, por sua vez, falar em igualdade (de inteligências) é uma aposta (política e filosófica) sobre a condição humana em sua potência, tendo em vista os efeitos que a visão de homem produz na experiência humana, dada a coerção que a negação desta acaba produzindo. Falar em igualdade, para Rancière, é o meio de guardar, para cada sujeito, o direito de exercer sua vontade, conforme as condições de vida que lhe sejam oferecidas nas distintas realidades sociais.

Deste modo, cada autor constrói uma versão distinta para a natureza humana, conforme a política específica que estabelece para a teoria que formula, ambos trazendo, porém, em suas proposições, a preocupação de dar lugar àquilo que, em cada sujeito ou em cada arranjo social, encontra-se submetido às forças sociais prevalentes, na busca de, em nosso entendimento, escutar o eco daquilo que fica submetido e silenciado nas distintas dimensões da experiência humana. Freud e Rancière usam políticas distintas. Um faz a defesa do sujeito psíquico a partir da diferença, o outro faz a defesa do sujeito político a partir da igualdade. A igualdade a que se referem, portanto, não é a mesma. Para Freud, a igualdade da natureza humana diz respeito à disposição psíquica, composição pulsional e desejante do inconsciente, fundamento da experiência de vida de cada sujeito. Para Rancière, igualdade é o princípio político e filosófico dos humanos em sua existência social, que se enuncia a partir da constatação de seu dano, ou seja, da experiência da desigualdade. Falar em igualdade é apontar e defender a condição de cada indivíduo como sujeito de direito à palavra, ao próprio desejo, na assembleia dos outros (Lacan, 1955-56/2002, p. 339). Ocorre que nem sempre distinguimos qual 
dimensão do sujeito está em pauta, bem como os usos desses significantes igualdade e diferenças - se prestam a interesses e disposições específicos na cena social, servindo de apoio a disputas de poder que lançam mão de saberes específicos, conforme as formulações do humano ali promovidas. Daí que o limiar entre essas áreas do saber, em seus usos, torna-se tênue.

Para a psicanálise, o diálogo com Rancière traz a possibilidade de considerar o risco que a defesa da singularidade e a ênfase na diferença comporta, ao servir de apoio à legitimação de hierarquias entre os humanos, conforme suas naturezas. Lança luz sobre os efeitos que um saber teórico pode produzir na cena social, conforme os usos que dele são feitos; problematiza a dimensão política que cada teoria carrega, na inscrição histórica e social que possui. Por último e sobretudo, permite investigarmos o campo de forças que acompanha toda formação coletiva que compõe cada organização social, reunindo indivíduos que se veem e não se veem como pares. Seguimos.

\section{$O$ ideal do consenso e a defesa da equidade}

Em outra vertente, numa perspectiva do consenso, Ricoeur se propõe a atribuir ao reconhecimento lugar de destaque na história da filosofia. Herdeiro da tradição habbermasiana da comunicação social, Ricoeur resgata a obra de Hegel como resposta à formulação de Hobbes acerca da natureza humana, da qual Freud se reconhece cúmplice. Em vez de sugerir a condição de disputa e ameaça como fundamento do encontro entre os humanos, resultando num estado de medo, que encontra no contrato social uma forma de evitar mal maior ao coletivo, Hegel, por meio do percurso da realização do Espírito, apresenta outra perspectiva para a experiência humana, na qual o outro, antes de ser uma ameaça, é objeto do interesse do sujeito na luta pelo reconhecimento que rege a condição humana (Ricoeur, 2006).

Próximo a Rancière nesse ponto, Ricoeur entende que o reconhecimento não seria originário da natureza, pois seria a experiência do menosprezo - entendida como ausência de reconhecimento - o provocador inicial da luta pelo reconhecimento, tornando-se essa a condição de existência para cada sujeito. Aqui, ser é ser para o outro, conforme a relação de dependência intrínseca do primeiro em relação ao último. A voz passiva se torna, então, a tradução direta da condição do sujeito, na qual ser reconhecido é a modalidade última do sujeito frente a seu objeto de desejo; em sua formulação plena, portanto, ser é ser reconhecido pelo outro. 


\section{LITERATURA, ARTE, CULTURA}

Para o filósofo, a dissimetria é originária da relação entre eu e o outro (Ricoeur, 2006), o que justifica a experiência do menosprezo como originária da luta pelo reconhecimento. No entanto - e aqui o autor expressa sua utopia —, é possível a superação momentânea dessa diferença de posições na mutualidade da experiência de reconhecimento, quando a alteridade da doação do eu ao outro, ao ser compartilhada, torna possível uma relação de reciprocidade, não mais regida pelo cálculo mercantil, pois é quando o preço que mede o valor de cada gesto perde sua função e sentido. É o momento de trégua na luta, quando é estabelecido um estado de paz fruto da certeza do reconhecimento que cada sujeito pode experimentar.

Apoiando-se em Honeth, Ricoeur discrimina três modalidades de reconhecimento, ampliando seu campo para além do entorno imediato de cada indivíduo. Esta seria apenas a primeira modalidade de reconhecimento, pautada em "laços afetivos fortes" em uma "gama de relações eróticas, de amizades ou familiares" (Ricoeur, 2006, p. 203). A segunda seria o reconhecimento estabelecido no plano jurídico, quando o respeito se torna norma e adquire amplitude universal, por meio dos direitos civis, sociais ou políticos, apoiando-se, em última instância, nos valores da igualdade e da liberdade como ditames que norteiam todos os direitos estabelecidos. Aqui se abre um vasto campo de discussão e ação social em torno da luta por reconhecimento no plano social, que busca legitimidade e institucionalidade como garantia de conquistas de direitos para indivíduos em coletividades. Se o semelhante pode não ser somente o rival de cada sujeito, a experiência no convívio social, entretanto, não chega a ser harmônica. Sentimentos de exclusão, opressão e humilhação atestam que o reconhecimento não é distribuído de modo equitativo. No entanto, cumprem no plano social a função que o menosprezo ocupa em cada relação entre indivíduos, na luta pelo reconhecimento, ao incitarem à indignação, sentimento que surge como impulso para a luta, em reação à perda de respeito vivida em sociedade. Quando dela resulta a conquista de direitos e o reconhecimento pode ser, então, socialmente legitimado, o orgulho emerge como fruto do respeito a si próprio, trazendo dignidade ao sujeito e, consequentemente, sustentação para sua condição social (p. 270). Este é o caminho para cada sujeito reconhecer-se digno de direitos e por desdobramento, responsável pelos direitos dos demais, conformando o compromisso de cada um em relação ao coletivo. É o momento da legitimação do corpo social enquanto tal, instaurando ali, entre todos, o reconhecimento do direito a ter direitos.

A terceira modalidade de reconhecimento considerada por Ricoeur é a estima social, descrita como sendo a aproximação mútua entre os indivíduos 
decorrente de sua convergência em torno de valores e finalidades. Esta aproximação apontada por Ricoeur faz lembrar a terceira modalidade de identificação (sem objeto definido), bem como a noção de ideal de massa (como ponto de convergência do imaginário social) descritos por Freud em "Psicologia de massas...", como mecanismos necessários para o funcionamento social. ${ }^{3}$ A aproximação apontada por Ricoeur estabelece, segundo esse autor, uma rede de reconhecimento mútuo, na medida em que ao perceber o outro como semelhante no compartilhamento de determinadas afinidades, ele logo se tornaria digno, para o sujeito, de seu reconhecimento. Também entendemos que tal processo não se daria fora do percurso acima descrito, por meio do qual há a conformação do campo de direitos para cada corpo social, mas seria parte dele, necessariamente.

Utopia? O percurso descrito por Ricoeur causa estranhamento para simpatizantes do argumento hobbesiano retomado por Freud acerca da condição humana em sociedade: um mal-estar decorrente do compromisso estabelecido para todo aquele que visa participar da lei da cultura, ao se ver obrigado a suportar o convívio com seus semelhantes que, até que provem o contrário, são seus rivais. Distintamente de Freud, o autor guarda a utopia 784 de enxergar no humano a disposição para a cumplicidade e o reconhecimento diante do outro, mesmo sendo ele um desconhecido. Aposta na viabilidade desse percurso, mesmo diante dos obstáculos enfrentados em cada uma dessas etapas que ainda assim tornariam possível alcançar, em reciprocidade e coletivamente, uma condição social organizada em torno de direitos universais pautados na igualdade e na liberdade. Mesmo que entenda a condição de reciprocidade como secundária às desigualdades que imperam na cena social, o autor identifica um estado de paz alcançado pelo sujeito, ao desfrutar da certeza do reconhecimento alcançado, como possível e necessário à sustentação de toda organização social.

Ricoeur (2006) não deixa de notar o desafio de sua aposta, ao apontar a predominância da desigualdade no mundo contemporâneo e a dificuldade

${ }^{3}$ A diferença de perspectivas de cada um não impede tal aproximação; Ricoeur, inspirado na comunicabilidade de Habermas, preocupa-se com a possibilidade efetiva de convergência entre muitos, como lastro para a sustentação. Freud, por sua vez, destaca os pontos de coesão que surgem na coletividade para mostrar ora labilidade ou o caráter imaginário de tais construções ("Psicologia de massas..."), ora o desamparo latente que subjaz aos arranjos coletivos ("O mal-estar na cultura"). 


\section{LITERATURA, ARTE, CULTURA}

da sustentação de uma distribuição equitativa entre direitos sociais e bens mercantis. Porém, ao defender sua aposta no plano da viabilidade, como ideal passível de consideração, evita o risco da crítica social que, ao não encontrar alternativas para dada condição social, vista como inevitável, acaba corroborando com a manutenção da realidade que denuncia (pois se não há saída, é preciso suportar).

Rancière e Ricoeur trazem versões distintas sobre a condição humana em sociedade, mas não de todo incompatíveis. No que tange a este trabalho, apresentam diretrizes para pensarmos na utopia de um encontro horizontal entre pares, em meio a hierarquias e dispositivos de ordenamento social. Acreditamos que além dos encontros aqui considerados (desse grupo de psicanalistas), tal discussão permite a análise desse tema num âmbito mais amplo, ao tratar do desafio de sustentação da palavra horizontal num universo desigual.

Rancière (2013) alerta para a impossibilidade do consenso em todo arranjo coletivo e o uso policial que se faz em seu nome. Logo, qualquer agrupamento realizado em um meio institucional está sujeito ao que chama de vontade de preponderância ou desejo de ser superior entre os indivíduos que dele participam, ou, ainda, é resultado do narcisismo das pequenas diferenças como provocador das infindáveis disputas grupais. A situação de desigualdade (de valor e de reconhecimento) instaurada num grupo em instituição é então fruto da imposição de uns sobre outros, como exercício de força daqueles que buscam se impor a seus semelhantes; é fruto de cada conjuntura e não da natureza dos sujeitos.

A noção de igualdade, em contrapartida, surge como experiência negativa, a partir de sua ausência. É ela que, fruto do menosprezo ou de suas variações, permite a indignação, conforme propõe Ricoeur, que opera a favor da reivindicação pelo direito à palavra na assembleia dos outros, aqueles que testemunham entre si os discursos alheios e disponibilizam (ou não) um lugar a cada um no corpo coletivo. Tomar a palavra é, então, um ato de reivindicação do reconhecimento do Outro, sempre incerto, sempre fugidio (ou mesmo impossível, como provoca Lacan, ao marcar a inexistência da relação), para viver a certeza de sua existência frente ao olhar do Outro (ilusão necessária e constituinte, como atesta o estádio do espelho), a fim de responsabilizar-se pelo coletivo. $\mathrm{O}$ uso da palavra é um ato no qual cada artesão não simplesmente "transmite seu saber (pois) ele poetiza, traduz e convida os outros a fazer a mesma coisa", tomando as palavras como instrumentos (Rancière, 2013, p. 96) para sua luta por reconhecimento em favor 
de um lugar de reciprocidade frente aos demais. Ao buscar reciprocidade, a reivindicação almeja a condição de igualdade entre pares e, por desdobramento, desses frente aos demais, conforme a frágil e tênue alteridade que cada coletivo é capaz de sustentar, quando uns e outros dispõem-se a ver-se como semelhantes na hierarquia de posições da qual participam. Esta é a utopia que cada palavra em uso guarda na experiência entre pares, em meio às tantas desigualdades com as quais todos convivemos.

\section{A frágil sustentação da palavra}

Buscamos o outro a partir de nossas inquietações diante do Outro, na esperança de encontrar eco às palavras que rasgamos em bilhetes dispostos em garrafas lançadas ao mar. Se o desamparo e o estranhamento são inevitáveis, em nossa existência e experiência de vida, tornam-se suportáveis apenas na medida em que haja uma lei (da cultura ou da família, como diria Antígona $^{4}$ ), que nos dê sustentação para tanto, funcionando assim como uma modalidade do reconhecimento instituída (aquela que garante os direitos de cada membro do corpo social).

Sabemos que nem sempre estamos dispostos a vermo-nos como semelhantes, quando nossas patologias nos convocam em suas demandas e nosso narcisismo exige suas compensações frente às questões prementes em cada arranjo coletivo. Quando nos reunimos como psicanalistas para falar sobre nosso exercício profissional, em nossos encontros das "Inquietações da clínica cotidiana", nos posicionamos frente a nossos pares a partir do reconhecimento que portamos da experiência transferencial vivida com cada paciente, cada qual reconhecedor em alguma medida do suposto saber que nos é inferido sobre nossa capacidade de escutar cada uma de suas questões. Porém, entre nossos pares, esse reconhecimento prévio é mais frágil, pois em torno de cada assembleia de analistas paira uma questão que rodeia a história da psicanálise em suas distintas correntes, permeia as disputas estabelecidas entre si ou

${ }^{4}$ Tragédia grega de Sófocles, na qual a personagem Antígona enfrenta as leis da cidade que então não permitam o sepultamento do irmão, que lutara na disputa pelo trono. Assim, ela se compromete com as leis da família em detrimento das leis da cultura. 


\section{LITERATURA, ARTE, CULTURA}

frente a outras práticas e saberes voltados aos cuidados do humano. Quais dispositivos, parâmetros e fundamentos específicos da prática psicanalítica e de sua teoria, atrelados entre si, a distinguiriam de outros saberes e práticas, permitindo a seus próprios praticantes reconhecerem-se como pares, diferenciando-se dos demais? Caso isso fosse possível, a quem caberia reconhecer como legítimos os portadores de tais referências, dispositivos ou parâmetros? São questões antigas, que acompanham a história da psicanálise desde seu nascimento, tendo o próprio Freud se detido sobre elas (1926/1992a). Muitos autores se debruçaram sobre o tema, a partir de distintas experiências institucionais psicanalíticas (por exemplo, Alberti, 2009).

Não há consenso possível entre aqueles que participam da hierarquia (formal ou informal) de uma instituição, seja ela qual for, pois cada arranjo institucional estabelece, de um modo ou de outro, desigualdades entre seus membros, rompendo a condição igualitária que os equalizaria como sujeitos de direitos naquele meio. Ainda assim, e talvez por isso mesmo, buscamos reconhecimento entre uns e outros. No caso específico de nossos encontros, propomos um espaço aberto a todos os membros do Departamento, a ser visitado também pelos pares de nossos pares, mesmo que não sejam do Departamento. Cada encontro possui uma nova configuração de analistas, que por sua vez relatam e problematizam distintas situações clínicas portadoras dos enigmas de uma prática sempre artesanal. Será que reconhecemos, a cada encontro e a cada participação, a pertinência e a legitimidade dos diferentes manejos e entendimentos apresentados, como próprios à psicanálise com a qual nos identificamos e que buscamos praticar? Será que creditamos todas as proposições de nossos colegas, nas distintas formulações que cada um apresenta? Cada um de nós também vive a incerteza e a incompletude das respostas de reconhecimento que recebemos de nossos pares, nas formulações que permitimos compartilhar. Não há consenso, constatamos.

Um campo incerto se instaura entre o que é reconhecido, o que é tolerável e o que não é tolerável $\left(\right.$ Eco, 1998) ${ }^{5}$ para cada um e para o arranjo que no coletivo impera, como tênue e desigual formação de compromisso estabelecida a cada momento. Há sempre uma incessante negociação entre cada um desses parâmetros, onde as formulações de uns servem como referência para outros se balizarem em seu exercício de reconhecimento; quem é reconhecido inicialmente é tomado aos olhos de seu reconhecedor como

${ }^{5}$ Agradecemos à Silvia Nogueira pela indicação desta referência. 
parâmetro para sua atribuição de novos reconhecimentos; a intolerância, em contrapartida, também se presta ao jogo de atribuições nas redes de não reconhecimento, promovendo desqualificação ou estigma, que por seu caráter ameaçador, tendem a ser negados ou silenciados. O tolerável está circunscrito aos parâmetros estabelecidos pelo narcisismo de cada um, em sua tênue e ambivalente borda que separa aquilo que se presta à identificação, admiração e compartilhamento e o que passa a ser alvo de recriminação e repulsa, combustível para a intolerância. Aqui se anuncia o desafio da alteridade que, como propõe Endo (2014), é "a convivência diante da impossibilidade de ser outro, somada à estranheza frente a essa impossibilidade e, ao mesmo tempo, o desejo - ou o dever — de suportar esse abismo" (pp. 80-81).

Cada palavra, em meio à assembleia, traz a sedução do reconhecimento e a vertigem do estranhamento. Entre ambas, há o desejo e a angústia, que se prestam como pontos de identificação a cada instante, perfazendo um cenário em caleidoscópio nas múltiplas configurações que se formam e se transformam entre reconhecimentos, tolerâncias e intolerâncias, encantamentos e hostilidades. Como suporte para tanto, há a memória de um espaço formalizado como ritual, encontro regular que marca em sua repetição o lastro de uma tolerância instituída, capaz de suportar (ou dar suporte) às silenciosas e fantasiadas intolerâncias pulsantes. Em meio ao dissenso inevitável, tem-se a possibilidade de identificação com um espaço simbólico compartilhado, frágil e potente na pluralidade pulsante que carrega, na ilusão que permite.

Agradecimentos: Aos inquietos Roberto Vilaboim, Roberta Kehdy, Natália Gola e Paulo Certain, pela parceria neste caldeirão reflexivo.

\section{Referências}

Alberti, S. et al. (2009). Ofício do psicanalista: formação versus regulamentação. São Paulo, SP: Casa do Psicólogo.

Bleger, J. (1991). O grupo como instituição e o grupo nas instituições. In R. Kaes et al. A Instituição e as Instituições: estudos psicanaliticos. São Paulo, SP: Casa do Psicólogo.

Eco, U. (1998). Cinco escritos morais. Rio de Janeiro, RJ: Record.

Endo, P. (2014). Preconceito e alteridade. Revista Brasileiros, novembro, 80-81.

Hilário, L. C. (2014, set.dez). A sombra marxiana em Freud, ou o descompasso 


\section{LITERATURA, ARTE, CULTURA}

constitutivo de um encontro. Psicologia \& Sociedade, 26(3), Belo Horizonte. https://doi.org/10.1590/S0102-71822014000300003.

Freud, S. (1992a). ¿Pueden los legos ejercer el análisis? Diálogos con un juez imparcial. In Obras Completas (Vol. 20, pp. 165-244, trad. J. L. Etcheverry). Buenos Aires, AR: Amorrortu. (Trabalho original publicado em 1926).

Freud, S. (1992b). El malestar en la cultura. In Obras Completas (Vol. 21, pp. 57-140 ; trad. J. L. Etcheverry). Buenos Aires, AR: Amorrortu. (Trabalho original publicado em 1930).

Freud, S. (1993a). Psicologia de las masas y análisis del yo. In: Obras Completas (Vol. 18, pp. 57-142; Trad. J. L. Etcheverry). Buenos Aires, AR: Amorrortu. (Trabalho original publicado em 1921).

Freud, S. (1993b). Nuevas conferencias de introducción al psicoanálisis. In Obras Completas (Vol. 22, pp. 1-168; trad. J. L. Etcheverry). Buenos Aires, AR: Amorrortu. (Trabalho original publicado em 1933).

Lacan, J. (2002). O seminário. Livro 3. As psicoses. Rio de Janeiro, RJ: Jorge Zahar. (Trabalho original publicado em 1955-56).

Laclau, E. (2013). A razão populista. São Paulo, SP: Três Estrelas.

Rancière, J. (1996). O desentendimento: politica e filosofia. São Paulo, SP: Ed. 34.

Rancière, J. (2013). O mestre ignorante: cinco lições sobre a emancipação intelectual ( $3^{\mathrm{a}}$ ed.). Belo Horizonte, MG: Autêntica.

Ricoeur, (2006). Percurso do reconhecimento. São Paulo, SP: Loyola.

\section{Resumos}

(The challenge of sustaining the word among peers: about politics and psychoanalysis)

Based on the experience of dialogue between psychoanalysts about clinical concerns, we discuss the challenge of sustaining the word among peers in the tensions, identifications and requests for recognition which thus emerge. We try to problematize the challenges that every person's narcissistic ambitions, in a scenario in which the positions among peers are not previously hierarchical, bring to the possibilities of horizontal linkage of reciprocity, showing the political dimension that affects group configurations. Our reflection process is based on an interdisciplinary dialogue between knowledge from different fields, between psychoanalysis and philosophy. We consider that between differences and equality, helplessness and the search for recognition, sustaining the word is a fragile resource that may give meaning to the subject's experience in the assembly of others.

Key words: Psychoanalysis, politics, singularity, equality, recognition 
(Le défi de la sustentation de la parole entre pairs : de la politique et de la psychanalyse)

A partir de l'expérience du dialogue établi entre psychanalystes à propos de problèmes cliniques, nous discutons le défi de la sustentation de la parole entre pairs, dans les tensions, identifications et demandes de reconnaissance qui en ressortent. Nous problématisons les défis que les ambitions narcissiques de chacun, dans un scénario où les positions entre pairs ne sont pas mises en hiérarchie d'avance, apportent aux possibilités de création de relations horizontales de réciprocité, en mettant en relief la dimension politique qui existe dans les configurations de groupes. Nous proposons cette réflexion à partir d'un dialogue entre différents savoirs, entre la psychanalyse et la philosophie. Nous concluons qu'entre différences et égalité, désarroi et recherche de reconnaissance, la sustentation de la parole est une ressource fragile capable de donner un sens à l'expérience du sujet dans l'assemblée des autres.

Mots clés: Psychanalyse, politique, singularité, égalité, reconnaissance

(El desafío de sostener la palabra entre iguales: sobre política y psicoanálisis)

Desde la experiencia del diálogo establecido entre psicoanalistas sobre inquietudes clínicas, hemos discutido el desafio de sostener la palabra entre iguales, en las tensiones, identificaciones y solicitudes de reconocimiento que de allí emergen. Dentro de un escenario en el que las posiciones entre pares no están previamente jerarquizadas, hemos buscado problematizar los desafios que traen las ambiciones narcisistas de cada uno en materia de posibilidades de creación de vínculos horizontales de reciprocidad, enseñando la dimensión política existente en configuraciones grupales. Para ello, hemos propuesto esta reflexión desde un diálogo interdisciplinario entre diferentes saberes, psicoanálisis y filosofía. Creemos que, entre diferencias e igualdades, vulnerabilidad y búsqueda por reconocimiento, sostener la palabra es el débil recurso que puede dar sentido a la experiencia del sujeto en la asamblea de los demás.

Palabras clave: Psicoanálisis, política, singularidad, igualdad, reconocimiento

Citação/Citation: Matheus, T. C. (2021, dez.). O desafio da sustentação da palavra entre pares: sobre política e psicanálise. Revista Latinoamericana de Psicopatologia Fundamental, 24(4), 776-791. http://dx.doi.org/10.1590/1415-4714.2021v24n4p776.14

Editora/Editor: Profa. Dra. Sonia Leite 


\section{LITERATURA, ARTE, CULTURA}

Submetido/Submitted: 17.8.2020/8.17.2020Ｒevisado/Revised: $21.1 .2021 / 1.21 .2021$

\section{Aceito/Accepted: 19.3.2021 / 3.19.2021}

Copyright: (C) 2009 Associação Universitária de Pesquisa em Psicopatologia Fundamental/ University Association for Research in Fundamental Psychopathology. Este é um artigo de livre acesso, que permite uso irrestrito, distribuição e reprodução em qualquer meio, desde que o autor e a fonte sejam citados / This is an open-access article, which permits unrestricted use, distribution, and reproduction in any medium, provided the original authors and sources are credited.

Financiamento/Funding: Este trabalho não recebeu apoio. / This work received no funding.

Conflito de interesses/Conflict of interest: $\mathrm{O}$ autor declara que não há conflito de interesses.

/ The author has no conflict of interest to declare.

Tiago Corbisier Matheus

Doutor em Psicologia Social pela Pontifícia Universidade Católica de São Paulo - PUC-SP (São Paulo, SP, Br); membro do Departamento de Psicanálise do Instituto Sedes Sapientiae (São Paulo, SP, Br); Professor e pesquisador da EAESP da Fundação Getúlio Vargas - FGV (São Paulo, SP, Br).

R. Fradique Coutinho, 1640/42

05416-002. São Paulo, SP, Br

tmatheus@uol.com.br; tiago.matheus@fgv.br

http://orcid.org/0000-0003-0430-2201

This is an open-access article, which permits unrestricted use, distribution,

(cc) BY-NC and reproduction in any medium for non-commercial purposes provided the original authors and sources are credited. 